\title{
DISTRIBUIÇÃO DE RAÍZES DE MAMOEIRO SOB DIFERENTES SISTEMAS DE IRRIGAÇÃO LOCALIZADA EM LATOSSOLO DE TABULEIROS COSTEIROS ${ }^{1}$
}

\author{
EUGÊNIO FERREIRA COELHO ${ }^{2}$, MARCELO ROCHA SANTOS ${ }^{3}$, MAURICIO ANTONIO COELHO FILHO ${ }^{4}$
}

\begin{abstract}
RESUMO - O sistema radicular de uma planta é responsável pela absorção de água do solo e deve ser considerado nos cálculos da quantidade de água necessária para irrigação. O trabalho teve por objetivo definir a distribuição do sistema radicular do mamoeiro irrigado por gotejamento e microaspersão em solo de Tabuleiro Costeiro do Recôncavo Baiano. Foram feitas duas trincheiras em diferentes posições relativas a duas plantas irrigadas por microaspersão e gotejamento superficial e enterrado a $0,25 \mathrm{~m}$, com as linhas laterais junto à fileira de plantas, com dois gotejadores por planta, cada um a 0,40 m de distância das mesmas. Na microaspersão, usou-se um emissor para duas plantas, entre duas fileiras simples. As amostras de raízes foram extraídas em malha de pontos nessas trincheiras de forma a abranger uma seção completa do sistema radicular. As raízes foram separadas do solo e digitalizadas em computador, sendo as imagens processadas por um aplicativo computacional que estimou o comprimento total e o diâmetro médio das mesmas em cada posição no perfil. O sistema radicular ocupou maior volume de solo na microaspersão em relação ao gotejamento, com maior concentração das raízes na direção do microaspersor. A profundidade efetiva do sistema radicular do mamoeiro irrigado por gotejamento superficial ou enterrado foi de $0,45 \mathrm{~m}$ e na microaspersão variou de $0,15 \mathrm{~m}$ na direção perpendicular à fileira de plantas a $0,35 \mathrm{~m}$ entre a planta e o microaspersor. Termos para indexação: gotejamento superficial, gotejamento enterrado, microaspersão, sistema radicular.
\end{abstract}

\section{PAPAYA ROOT DISTRIBUTION UNDER DIFFERENT TRICKLE IRRIGATION SYSTEMS INA COAST TABLE LAND LATOSSOL}

ABSTRACT - The root system is responsible for water uptake and should be considered in irrigation water requirement calculations. The work had as objective to define papaya root distribution under sprayer and drip irrigation in a Tableland Coast Soil of Recôncavo Baiano. Two trenches were dug at different positions related to plants irrigated by sprayer and surface and buried drip irrigation. The lateral lines irrigation were set close to the plant row with two emitters per pant, each one at $0.40 \mathrm{~m}$ from plant. In case of sprayer, it was used one emitter per two plants located between two single rows. Root samples were collected from a grid of points in these trenches in order to cover a complete section of the root system. Roots were separated from soil material and digitized in a computer and the images were processed by a software that estimated the total root length and mean diameter at each position of the grid in the soil profile. Root system has occupied larger volume of soil under microsprinkler compared to under drip irrigation with larger root concentration in the direction of the emitter. The effective papaya root depth under surface or buried drip irrigation was $0.45 \mathrm{~m}$ and varied from $0.15 \mathrm{~m}$ between plant rows to $0.35 \mathrm{~m}$ between the plant and the emitter.

Index terms: drip irrigation, buried drip irrigation, sprayer irrigation, root system

O mamoeiro é cultivado em quase todos os Estados brasileiros, com concentração da produção na Bahia, Espírito Santo, Ceará, Paraíba, Pará e Amazonas, que respondem por cerca de $75 \%$ da produção nacional (Agrianual, 2002).

Os cálculos da lâmina líquida ou bruta de irrigação para qualquer cultura levam em consideração a profundidade efetiva do sistema radicular (Bernardo, 1986). O uso equivocado da profundidade efetiva do sistema radicular pode trazer erro considerável a um projeto de irrigação. Vieira (1996) estabeleceu a profundidade efetiva do sistema radicular como aquela até onde se concentra pelo menos $80 \%$ das raízes.

Nas regiões de Tabuleiros Costeiros, a concentração do sistema radicular do mamoeiro encontra-se num raio de $0,35 \mathrm{~m}$ a partir do tronco da planta, sendo que esses valores podem variar em função da textura e da estrutura do perfil do solo (Coelho et al., 2000). Normalmente, os estudos do sistema radicular das culturas são voltados para as condições de sequeiro, quando não são direcionados para irrigação por aspersão. Em se tratando de irrigação localizada, como gotejamento e microaspersão, apenas o conhecimento da profundidade efetiva do sistema radicular não é suficiente para inferir as zonas de absorção de água e nutrientes, uma vez que a geometria de distribuição de água no solo nesse tipo de irrigação é de caráter multidimensional, diferindo do caráter unidimensional da irrigação por aspersão. Assim, em irrigação localizada, é necessário conhecer tanto a profundidade efetiva como a distância horizontal efetiva das raízes em relação à planta. $\mathrm{O}$ conhecimento da distribuição do sistema radicular é também necessário para o posicionamento adequado dos sensores utilizados no monitoramento da água do solo no manejo da irrigação. Nesse caso, a instalação dos sensores deve ser na região de maior concentração das raízes da planta.

O objetivo do trabalho foi avaliar a concentração e a distribuição das raízes do mamoeiro irrigado por gotejamento e microaspersão em latossolo dos Tabuleiros Costeiros do Recôncavo Baiano.

O experimento foi instalado em agosto de 1999, em Cruz das Almas-BA, latitude $12^{\circ} 48^{\prime} \mathrm{S}$, longitude $39^{\circ} 06^{\prime} \mathrm{W}$ e altitude de $225 \mathrm{~m}$, numa condição de clima úmido a subúmido, com pluviosidade média anual de $1.143 \mathrm{~mm}$ (D’Angiollela et al., 1998), utilizando-se da cultivar de mamoeiro (Carica papaya L.) Sunrise Solo do grupo Solo, no espaçamento 3,6 m x 2,0 $\mathrm{m} \mathrm{x} \mathrm{1,8} \mathrm{m.} \mathrm{O} \mathrm{experimento} \mathrm{foi} \mathrm{conduzido} \mathrm{em} \mathrm{um} \mathrm{Latossolo} \mathrm{Amarelo}$ distrófico típico (Souza \& Souza, 2001), textura franco-argilo-arenosa, contendo em média, na camada de $0-0,20 \mathrm{~m}, 643 \mathrm{~g} \cdot \mathrm{kg}^{-1}$ de areia total, 81 g.kg-1 de silte e 276 g.kg-1 $^{-1}$ de argila. Na camada de $0,20-0,40 \mathrm{~m}$, o solo apresentou 579 g. $\mathrm{kg}^{-1}$ de areia total, $108 \mathrm{~g} . \mathrm{kg}^{-1}$ de silte e $313 \mathrm{~g} . \mathrm{kg}^{-1} \mathrm{de}$ argila. O clima da região é classificado como úmido a subúmido, pluviosidade média anual de $1.143 \mathrm{~mm}$ (D’Angiollela et al., 1998).

O trabalho consistiu na avaliação do sistema radicular do mamoeiro sob três sistemas de irrigação localizada: gotejamento superficial, com a linha lateral junto à fileira de plantas; gotejamento enterrado, com a linha lateral a $0,25 \mathrm{~m}$ de profundidade, junto à fileira de plantas, e microaspersão com um emissor para duas plantas. No gotejamento superficial, foram utilizados emissores autocompensantes de $4 \mathrm{~L} \mathrm{~h}^{-1}$ e, no caso do gotejamento enterrado, de $2 \mathrm{~L} \mathrm{~h}^{-1}$. Os emissores, em número de dois por planta, foram instalados eqüidistantes do caule, cada um a 0,40 m do tronco na direção longitudinal à fileira de plantas, com base em recomendação de Goldberg et al. (1976). Na microaspersão, usou-se um emissor autocompensante de $47 \mathrm{~L} \mathrm{~h}^{-1}$ para duas plantas, de raio de ação de 3,0 m, com a linha lateral entre duas fileiras. A coleta de raízes foi feita aos 19 meses após o plantio, pelo método dos monolitos (Bohm, 1979), em que se usou um amostrador cilíndrico de aço galvanizado de $0,10 \mathrm{~m}$ de diâmetro, com uma abertura lateral. As posições de amostragem foram tomadas a partir de $0,15 \mathrm{~m}$ do tronco da planta, afastando-se do mesmo a cada $0,10 \mathrm{~m}$, até $1,55 \mathrm{~m}$. As profundidades

\footnotetext{
(Trabalho 076/2004). Recebido: 24/06/2004. Aceito para publicação: 22/02/2005.

${ }^{2}$ Pesquisador III, Embrapa Mandioca e Fruticultura, Caixa Postal 07, 44380-000, Cruz das Almas-BA. E-mail:ecoelho@cnpmf.embrapa.br.

${ }^{3}$ Estudante de Agronomia, Escola de Agronomia, UFBA, Campus Cruz das Almas, 44380-000, Cruz das Almas-BA.

${ }^{4}$ Eng. Agrônomo, D.Sc. Embrapa Mandioca e Fruticultura, Caixa Postal 07, 44380-000, Cruz das Almas-BA. Bolsista RD, CNPq, E-mail: macoelho@ cnpmf.embrapa.br.
} 

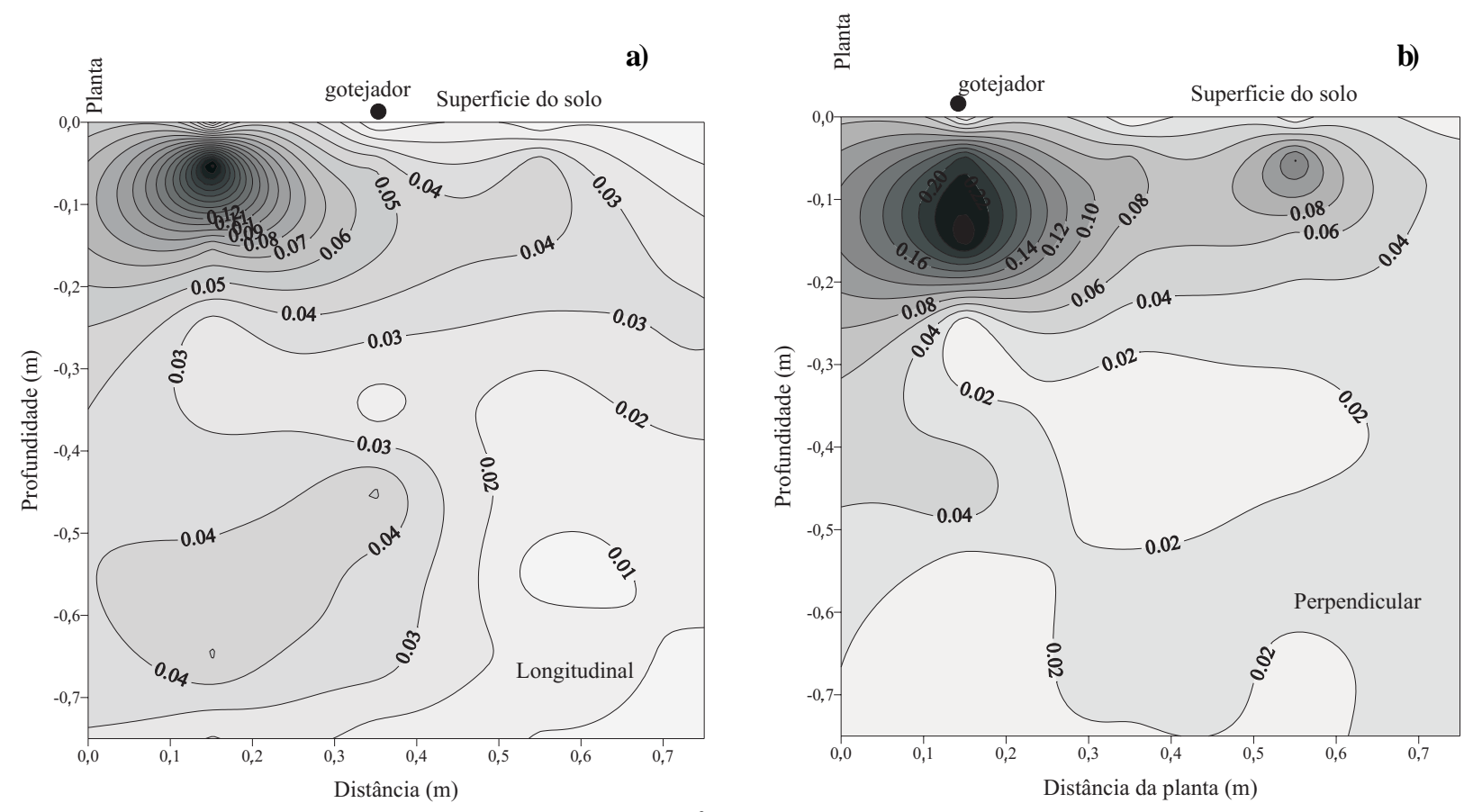

FIGURA 1 - Isolinhas de densidade de comprimento de raízes $\left(\mathrm{cm} \mathrm{cm}^{-3}\right)$ em perfis bidimensionais referentes a trincheiras abertas longitudinalmente (a) e perpendicularmente à fileira de plantas (b).

amostradas em cada posição tiveram incrementos de $0,10 \mathrm{~m}$, iniciandose na superfície do solo até a profundidade de $0,75 \mathrm{~m}$. Foram selecionadas duas plantas em cada sistema de irrigação e, para cada planta, foram coletadas raízes em duas direções radiais à planta: uma longitudinal e outra perpendicular à fileira de plantas. No caso da microaspersão, as amostras foram retiradas a partir da planta na direção perpendicular à fileira e em direção ao emissor. Após retiradas, as amostras foram colocadas em sacos plásticos e levadas ao laboratório onde as raízes foram separadas do solo por lavagem com água. Uma vez separadas, as raízes de cada posição no perfil do solo foram classificadas conforme os diâmetros dos segmentos e colocadas em folhas de transparências. Estas, contendo as raízes, foram, em seguida, levadas a um "scanner" e digitalizadas (Kaspar \& Ewing, 1997; Coelho \& Or, 1999) em arquivos TIFF comprimidos ("Tagged Image File Format").

Os arquivos TIFF foram, em seguida, descomprimidos e submetidos ao aplicativo Rootedge (Kaspar \& Ewing, 1997), para a determinação das características geométricas: comprimento e diâmetro das raízes. O comprimento das raízes, $\mathrm{Lr}(\mathrm{cm})$, foi usado para a determinação da densidade de comprimento de raízes, DCR $\left(\mathrm{cm} . \mathrm{cm}^{-3}\right)$, para um volume de amostra $\operatorname{Vr}\left(\mathrm{cm}^{3}\right)$, sendo a $\mathrm{DCR}=\mathrm{Lr} / \mathrm{Vr}$.

A distribuição de raízes do mamoeiro irrigado por gotejamento superficial (Figura 1) demonstra o efeito deste sistema de irrigação no padrão de distribuição das raízes. A região do perfil do solo imediatamente abaixo ou próxima do gotejador, limitada pela profundidade de $0,25 \mathrm{~m}$, e a distância da planta de $0,35 \mathrm{~m}$ foi a de maior densidade de

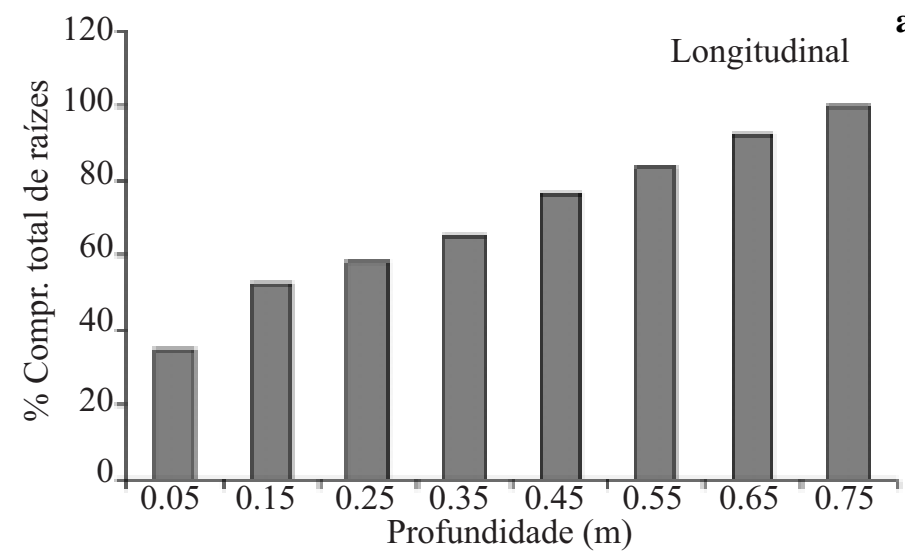

comprimento de raiz. Na direção da fileira de plantas (Figura 1a), onde estava a linha lateral com os gotejadores, houve maior expansão lateral das raízes, o que era esperado, pela maior umidade nesta região do solo. A profundidade efetiva do sistema radicular nas duas direções radiais à planta, equivalente a $80 \%$ do comprimento total das raízes, ocorreu para a profundidade de $0,45 \mathrm{~m}$, sendo que, pelo menos, $60 \%$ das raízes se concentraram à profundidade de $0,25 \mathrm{~m}$ (Figura 2). A densidade de comprimento de raízes (DCR) foi igual ou superior a $0,04 \mathrm{~cm} \mathrm{~cm}^{-3}$ para distâncias da planta entre $0,60 \mathrm{~m}$ e $0,70 \mathrm{~m}$, sendo estas distâncias superiores às reportadas por Coelho et al. (2000) para mamoeiro, o que se deve à condição irrigada, com umidade contínua nestas distâncias.

No gotejamento enterrado, houve um deslocamento vertical para baixo da região de maior concentração de raízes (Figura 3a). A maior DCR ocorreu na profundidade de $0,10 \mathrm{~m}-0,30 \mathrm{~m}$ e entre $0,10 \mathrm{~m}$ e $0,65 \mathrm{~m}$ de distância da planta, mas com maior concentração entre $0,10 \mathrm{~m}$ e 0,45 $\mathrm{m}$. Mais de $60 \%$ do comprimento total das raízes foi encontrado até a profundidade de $0,15 \mathrm{~m}$ e $92 \%$ do total das raízes até a profundidade de $0,25 \mathrm{~m}$ (Figura $3 \mathrm{~b}$ ). O deslocamento do centro de concentração de raízes se deve à distribuição de água gerada pelo gotejador enterrado a $0,25 \mathrm{~m}$, reforçando o fato de as raízes se concentrarem na região de maior umidade e terem a DCR reduzida à medida que se afastam dessa região. Apesar do deslocamento da região de concentração do sistema radicular, observouse menor raio de abrangência dessa região em profundidade.

A distribuição das raízes no solo irrigado por microaspersão ocupou maior volume comparada ao gotejamento, principalmente na região

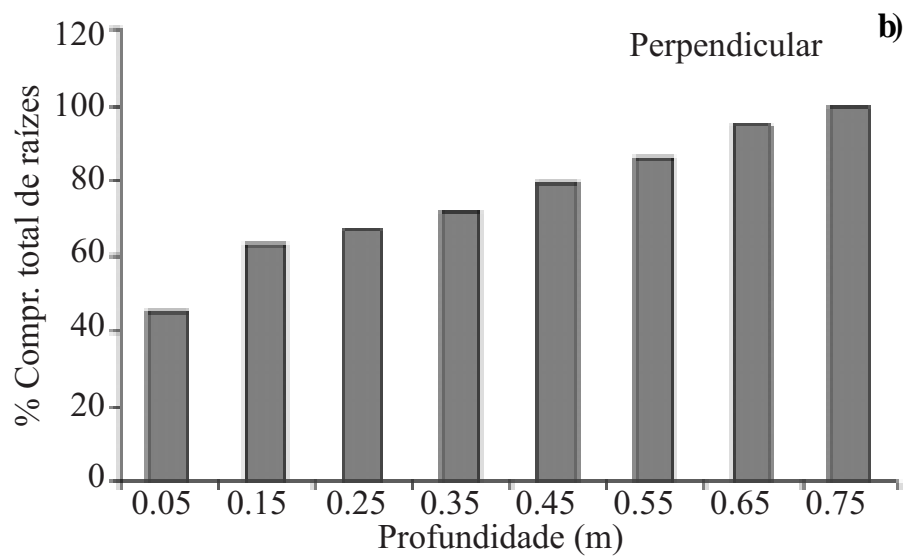

FIGURA 2 - Percentagem do comprimento total das raízes longitudinalmente (a) e perpendicularmente (b) à linha de plantio a diferentes profundidades do solo para o mamoeiro irrigado por gotejamento superficial. 


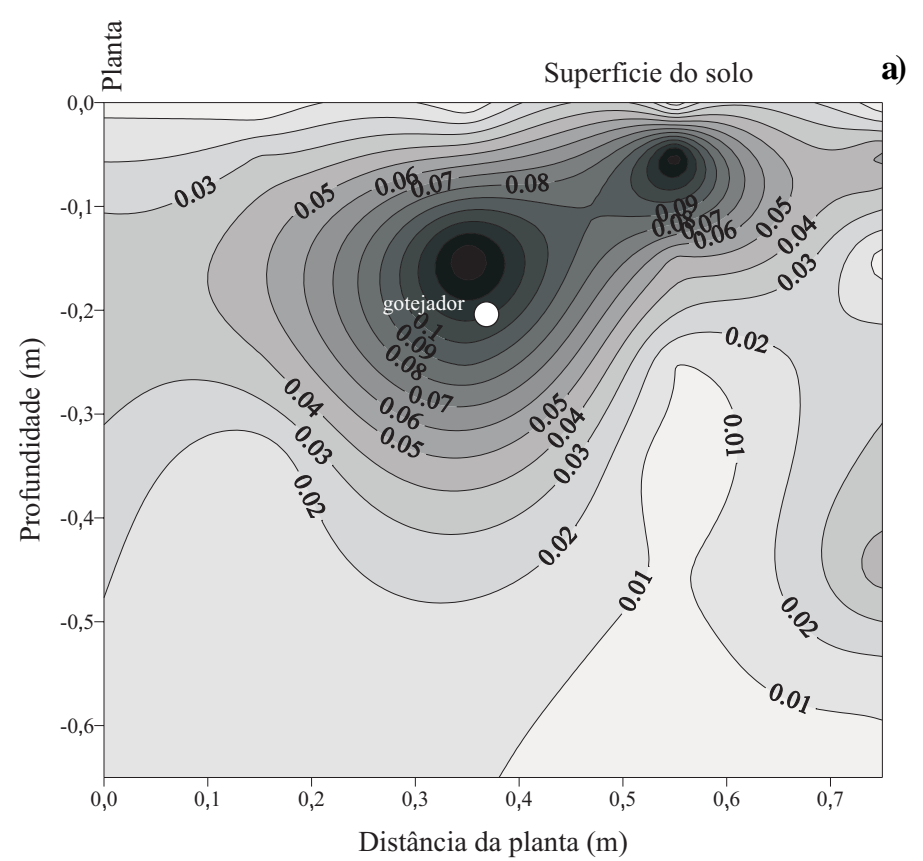

b)

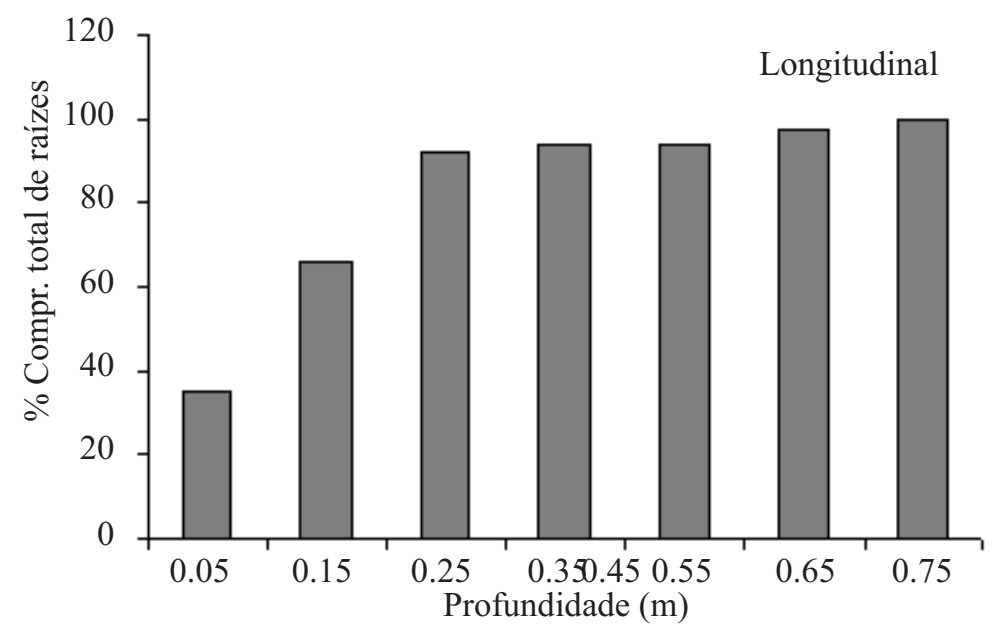

FIGURA 3 - Isolinhas de DCR $\left(\mathrm{cm} \mathrm{cm}^{-3}\right)$ no perfil longitudinal à fileira de plantas irrigadas por gotejamento enterrado (a). Percentagem do comprimento total das raízes a diferentes profundidades do solo para o mamoeiro irrigado por gotejamento enterrado (b).

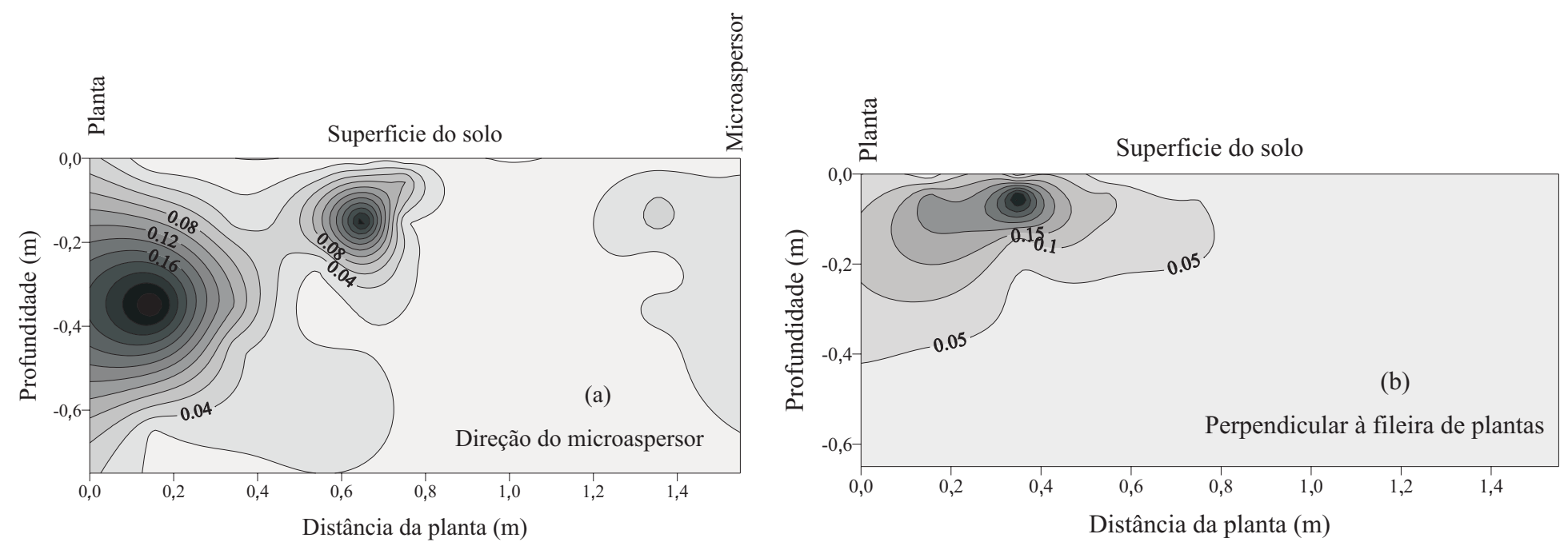

FIGURA 4 - Isolinhas de DCR $\left(\mathrm{cm} \mathrm{cm}^{-3}\right)$ obtidas nas trincheiras abertas na direção do microaspersor (a) e na direção perpendicular à fileira de plantas (b).
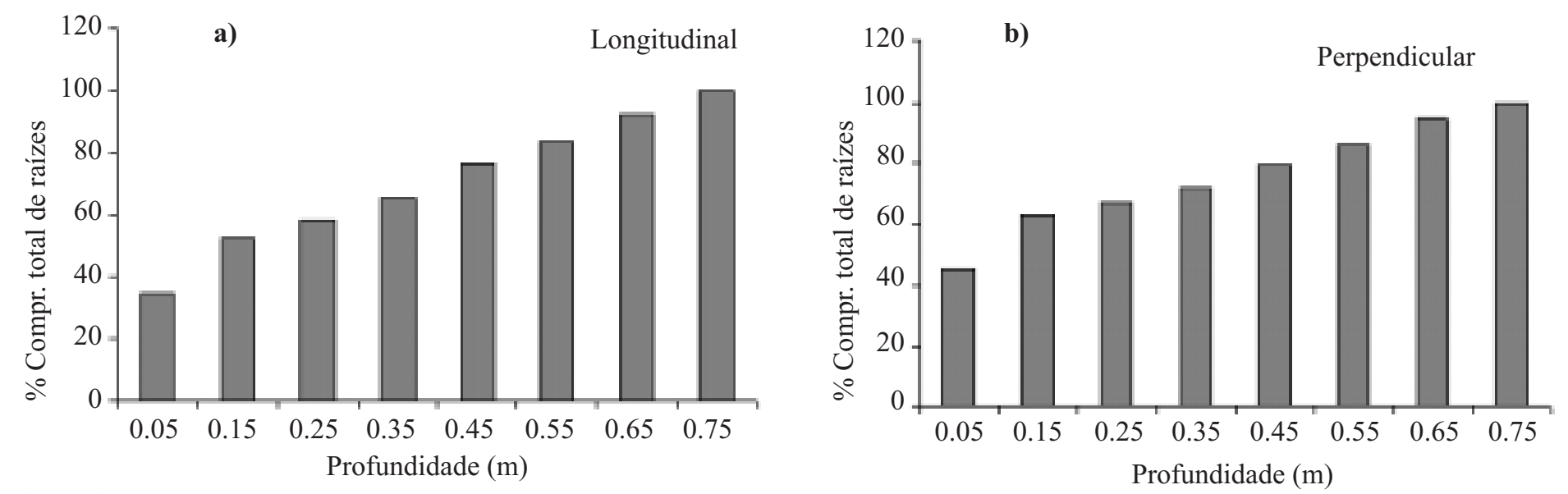

FIGURA 5 - Variação percentual do comprimento total das raízes a diferentes profundidades do solo para o mamoeiro irrigado por microaspersão, em dois perfis, um entre a planta e o microaspersor (a), e o outro perpendicular à fileira de plantas (b).

entre a planta e o microaspersor, onde as raízes atingiram profundidades superiores a 0,60 m e distância da planta de $0,80 \mathrm{~m}$ (Figura 4a).

A máxima DCR ocorreu nas profundidades entre $0,25 \mathrm{~m}$ e 0,45 $\mathrm{m}$. No perfil do solo perpendicular à fileira de plantas (Figura 4b), a região de concentração de raízes atingiu a mesma distância da planta, mas em menor profundidade (até $0,40 \mathrm{~m}$ ). A máxima DCR foi observada entre $0-0,10 \mathrm{~m}$ de profundidade e distâncias entre $0,25 \mathrm{~m}$ e $0,45 \mathrm{~m}$ da planta. Esses resultados ocorreram devido à maior área e volume de 
solo molhado pela microaspersão, principalmente entre a planta e o microaspersor. $\mathrm{O}$ perfil perpendicular à fileira de plantas correspondeu à região onde caiu menor volume de água, o que resultou em menor abrangência do sistema radicular e menor profundidade do mesmo. A profundidade efetiva do sistema radicular, ou a profundidade correspondente a $80 \%$ do comprimento total, foi de $0,45 \mathrm{~m}$ no perfil perpendicular à fileira de plantas e de $0,55 \mathrm{~m}$ entre a planta e o microaspersor (Figura 5).

Um dos resultados práticos da distribuição de raízes consiste na definição do posicionamento dos sensores para o monitoramento da água do solo feita com base nas zonas de maior atividade do sistema radicular, coincidentes com as regiões de maiores DCR. Estas zonas ficaram definidas entre $0-0,20 \mathrm{~m}$ de profundidade a distâncias entre 0,10 $-0,30 \mathrm{~m}$ da planta para o gotejamento superficial, entre $0,10-0,30 \mathrm{~m}$ de profundidade e distância da planta de $0,20-0,40 \mathrm{~m}$ para o gotejamento enterrado. Na microaspersão, estas zonas ficaram definidas entre 0,25 $0,45 \mathrm{~m}$ de profundidade, até $0,35 \mathrm{~m}$ entre a planta e o microaspersor.

$\mathrm{O}$ estudo mostrou que a distribuição de raízes do mamoeiro irrigado segue padrões no solo determinados basicamente pelo tipo do sistema de irrigação. O sistema radicular ocupou maior volume de solo na microaspersão em relação ao gotejamento, com maior concentração das raízes na direção do microaspersor. A profundidade efetiva do sistema radicular do mamoeiro irrigado por gotejamento superficial ou enterrado foi de 0,45 m e na microaspersão variou de $0,15 \mathrm{~m}$ na direção perpendicular à fileira de plantas a $0,35 \mathrm{~m}$ entre a planta e o microaspersor.

\section{REFERÊNCIAS}

AGRIANUAL 2002: anuário da agricultura brasileira. São Paulo: FNP, Consultoria e Comércio, 2001.536p.

BERNARDO, S. Manual de irrigação.5. ed.Viçosa: UFV Impr. Univ., 1986. 596p.

BOHM, W. Methods of studing root systems. New York: Springer Verlag, 1979. 190p
COELHO,E.F.; SILVA, J. G. F. da.; SOUZA, L. F. de. Irrigação e fertirrigação. In: TRINDADE, A.V. (Org.). Mamão produção aspectos técnicos. Brasília, DF: Embrapa Comunicação para Transferência de Tecnologia, 2000. p.37-42 (Frutas do Brasil, 3).

COELHO, E.F.; OR, D. Root distribution and water uptake patterns of corn under surface and subsurface drip irrigation. Plant and Soil, Dordrecht, v.206, p.123-136, 1999.

D'ANGIOLLELA, G. L. B.; CASTRO NETO, M. T.; COELHO, E. F. Tendências Climáticas para os Tabuleiros Costeiros da Região de Cruz das Almas In: CONGRESSO BRASILEIRO DE ENGENHARIA AGRÍCOLA, 27., 1998. Poços de Caldas. Anais... v.1, p.43-45.

GOLDBERG, D.; GORNAT, B.; RIMON, D. Drip irrigation: principles design and agricultural pratices. Telaviv: Drip Irrigation Scientific Publications, 1976. 296p.

KASPAR, T. C.; EWING, R. P. Rootedge: software for measuring root length from desktop scanner images. Agronomy Journal, Madison, v.89, p. 932-940, 1997.

KLEPPER, B. Origin, branching and ditribution of root systems. In: GREGORY, P.J.; LAKE, J.V.; ROSE, D.A. Root development and function. New York: Cambridge University Press, 1987. p.103-123.

MEDINA, J.C. Cultura. In: MEDINA, J.C.; BLEINROTH, E.W.; SIGRIST, J.M.M.; MARTIN,Z.J. de; NISIDA, A.L.A.C; BALDINI, V.L.S.; LEITE, R.S.S.F.; GARCIA. A.E.B. Mamão: cultura, matéria-prima, processamento e aspectos econômicos. Campinas: ITAL, 1989. p. 178

SOUZA, L. da S.; SOUZA, L.D. Caracterização físico-hídrica de solos da área do Centro Nacional de Pesquisa de Mandioca e Fruticultura Tropical. Cruz das Almas. Bahia. Cruz das Almas: EMBRAPACNPMF. 2001.56p. (Boletim de Pesquisa, 20).

VIEIRA, D.B.; GENOVEZ, A.M.; GOMES, E.M. Determinação da profundidade efetiva do sistema radicular do milho (Zea mays L.) irrigado. In: CONGRESSO NACIONAL DE IRRIGAÇÃO E DRENAGEM, 11., 1996, Campinas. Anais... Campinas: ABID, 1996. p.95-106. 